\title{
SIZE OF BOEHMITE NANOPARTICLES BY TEM IMAGES ANALYSIS
}

\author{
MAXIME MOREAUd ${ }^{1}$, RENAUd REVEL ${ }^{1}$, DOMINIQUE JEULIN ${ }^{2}$ AND VINCENT MORARD ${ }^{1}$ \\ ${ }^{1}$ IFP-Lyon, rond-point de l'échangeur de Solaize, B.P. 3 - 69360 Solaize, France; ${ }^{2}$ Centre de Morphologie \\ Mathématique, Mathématiques et Système, Mines ParisTech, 35, rue Saint Honoré, 77305 Fontainebleau, France \\ e-mail: maxime.moreaud@ifp.fr; renaud.revel@ifp.fr, dominique.jeulin@ensmp.fr; vincent.morard@ifp.fr \\ (Accepted August 18, 2009)
}

\begin{abstract}
Transition aluminas, and especially the gamma type, are largely used as catalyst supports in refining and petrochemicals. Most studies focus on properties resulting from material texture and casting (specific surface, porous volume, pore shape and diameter). However, surface properties of alumina should be considered as well, as the catalytic activity is tightly related to the structure of exposed crystalline faces. As $\gamma$ alumina results from controlled thermal treatment of boehmite $\gamma$-AlOOH by a topotactic transformation, the nature of exposed crystalline planes is related to the starting material. Therefore, the synthesis of the oxihydroxide $\gamma-\mathrm{AlOOH}$, and especially size and shape of these particles, is critical in determining the relevant surface properties. Unlike often aggregated alumina, boehmite nanoparticles can be observed by TEM. Analysis of these TEM images can be performed to estimate the size of the boehmite nanoparticles. Information about morphology of the nanoparticles is obtained by the analysis of the covariance, modeling micrographs by a dilution model.
\end{abstract}

Keyword: covariance, dilution model, nano-particles, TEM.

\section{INTRODUCTION}

Since one of the most fundamental characteristics of nanoparticle systems is their very high surface-tovolume ratio, controlling the size and surface properties of oxide nanoparticles, ie. their morphology, is of great importance. For instance, catalytic activity is closely related to the particle size and the type of exposed crystalline faces (Ahmadi et al., 1996; Digne et al., 2002; Euzen et al., 2002; Arrouvel et al., 2004). Optical properties are strongly dependent on the particle size, because quantum size effects govern the energy of the electronic band gap and the phonon confinement (Brus, 1991). The size, shape and surface effects play a crucial role in the magnetic properties, governing the superparamagnetic relaxation and the coercivity (Dormann et al., 1997). The liquid crystal behavior of aqueous dispersions of oxide particles (Lemaire et al., 2002; Dessombz et al., 2007) is strongly dependent on the particle morphology, because the axis ratio governs both the particle dispersion and their mutual interactions. Recent research evidenced anisotropic photocatalytic properties induced by rod-like $\mathrm{TiO}_{2}$ rutile in oriented films (Dessombz et al., 2007).

Given the importance of particle morphology as a key parameter in designing and controlling material properties, size and shape accurate characterization attracts a great deal of attention. Various techniques are extensively used for this purpose, each with their own advantages and disadvantages. Transmission electron microscopy (TEM), X-ray diffraction (XRD), smallangle X-ray scattering (SAXS), and dynamic light scattering (DLS) constitute the most frequently exploited methods for size and shape determination (Wagner et al., 2000; Borchert et al., 2005; Chiche et al., 2008). SAXS can theoretically allow a complete determination of nanoparticle morphology (Espinat $e t$ al., 1993). However, sample polydispersity induces an important bias at small angles of scattering, and the use of SAXS is limited to size determination, and in some extent to particle anisotropy (Vigolo et al., 2002). Direct observation techniques providing real images of particles are more adapted to shape determination.

TEM and high resolution TEM (HRTEM) are currently the most widely used techniques to study nanoparticles morphology (Buffat et al., 1991; Zhang et al., 2003; Jolivet et al., 2004a; b; Moreaud et al., 2008a). If TEM provides two-dimensional picture of observed samples, 3D TEM has also been developed to get more relevant information about the morphology and particle depth (Ziese et al., 2004; Moreaud et al., $2008 \mathrm{~b}$ ). However, in some cases TEM observations are far from being straightforward. Many common problems complicate observations, including the 
overlap of particles, lack of contrast, and data processing of TEM pictures. Our purpose is to explain how we can use TEM and a random model to obtain information about the size of observed nanoparticles. We apply this approach to boehmite $\mathrm{AlOOH}$ nanoparticles.

\section{EXPERIMENTAL}

Boehmite is provided by Sasol Germany $\mathrm{GmbH}$ under the name Disperal 40. Information available about this material give a particle size of $50 \mu \mathrm{m}$ (D50) and a crystallite size of $40 \mathrm{~nm}$ (measured for (120) line by XRD). High resolution transmission electron micrographs (HR-TEM) were performed on a JEOL $2100 \mathrm{~F}$ at an acceleration voltage of $200.0 \mathrm{kV}$. The nanoparticles were simply ultrasonicated in ethanol and dispersed on carbon covered $\mathrm{Cu}$-grids. The acquired images have a resolution of $0.41 \mathrm{~nm} /$ pixel.

\section{NOISE REDUCTION AND IMAGE ARTEFACTS REMOVING}

Due to the acquisition, TEM images contain electronic noise and white diffraction artefacts localized on the edges of the boehmite nanoparticles (Fig. 2a). A succession of filters are performed in order to improve without damage the image quality of the edge transitions and the grey level intensities corresponding to the nanoparticles:
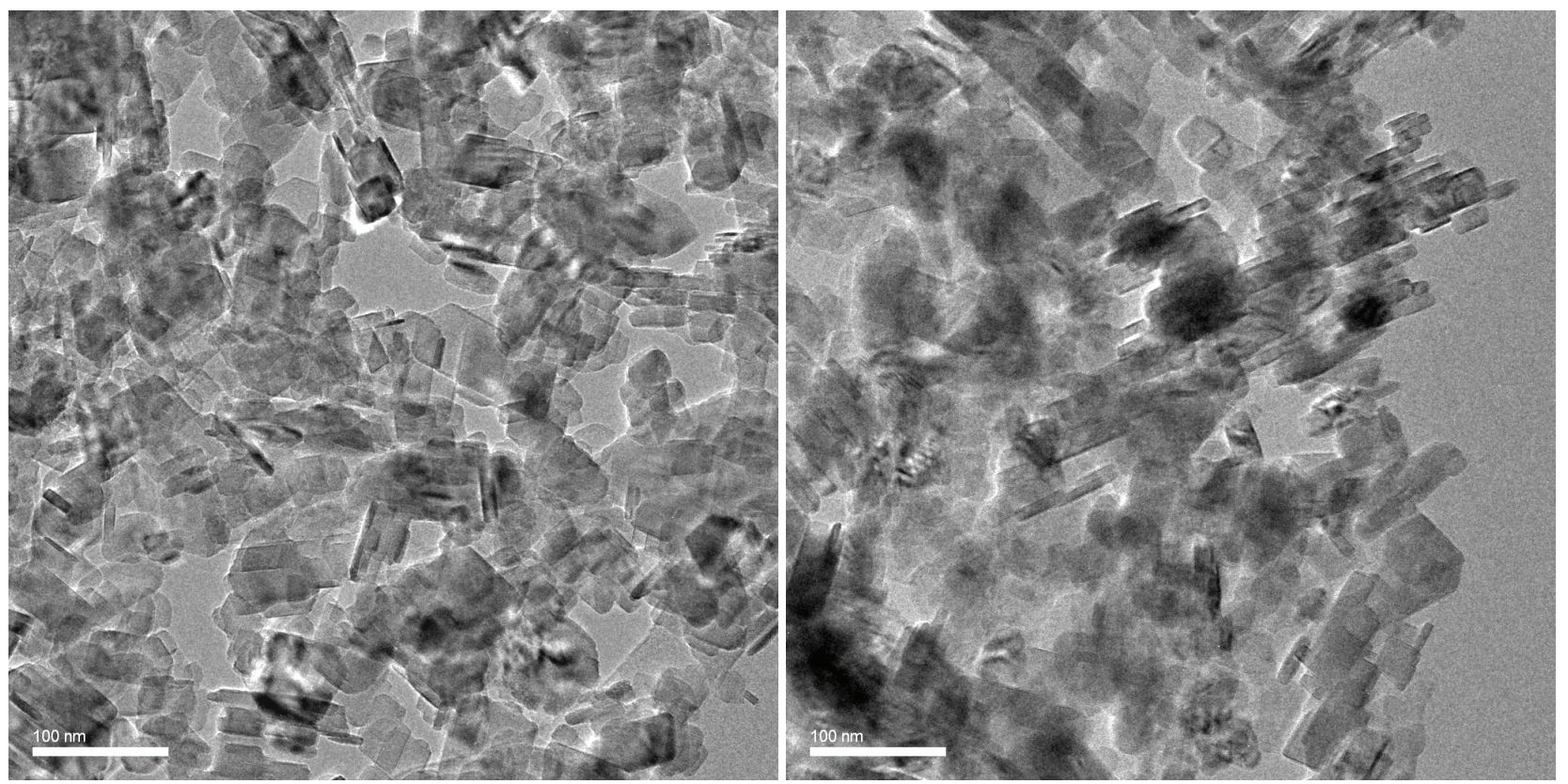

- A median filter of size $3 \times 3$ pixels is used to eliminate electronic noise of size one pixel (Fig. 2b).

- A bilateral filter (Tomasi and Manduchi, 1998) is then performed to smooth and reduce the remaining noise while preserving edges (Fig. 2c). It is a nonlinear and non iterative filter. It derives from a blur filter but it prevents blurring across edges by decreasing the weight of pixels when the intensity difference is too large. The output $\mathrm{O}$ of the bilateral filter for an image I with spatial support $\mathrm{D}$ and a pixel $\mathrm{x}$ is given by:

$$
O(x)=\frac{1}{k(x)} \sum_{y \in D} f(x-y) g(I(x)-I(y)) I(x)
$$

with

$$
k(x)=\sum_{y \in D} f(x-y) g(I(x)-I(y)) .
$$

Several edge-stopping functions can be used for $\mathrm{f}$ and $g$ such like Gaussian functions, or Tukey's biweight function which is statistically more robust to noise (Black et al., 1998). In our case, the best results are obtained using this last one with parameters $\sigma=5$ and 20 for $f$ and $g$ respectively:

$$
f(x)=g(x)=\left\{\begin{array}{ll}
\frac{1}{2}\left[1-\left(\frac{x}{\sigma}\right)^{2}\right]^{2} & |x| \leq \sigma \\
0 & \text { otherwise }
\end{array} .\right.
$$

Fig. 1. MET images of boehmite nanoparticles (Disperal 40, Sasol Germany GmbH). Image resolution: 0.41 nm/pixel. 
In the literature, several fast implementation of this filter are proposed (Paris and Durand, 2009; Durand and Dorsey, 2002). An approximate formulation is used, which linearizes the filter and performs a direct convolution (Pham and van Vliet, 2005).

- White artefacts localized on the edges of the nanoparticles have a size of approximately 3.3 $\mathrm{nm}$. To remove them, a morphological opening

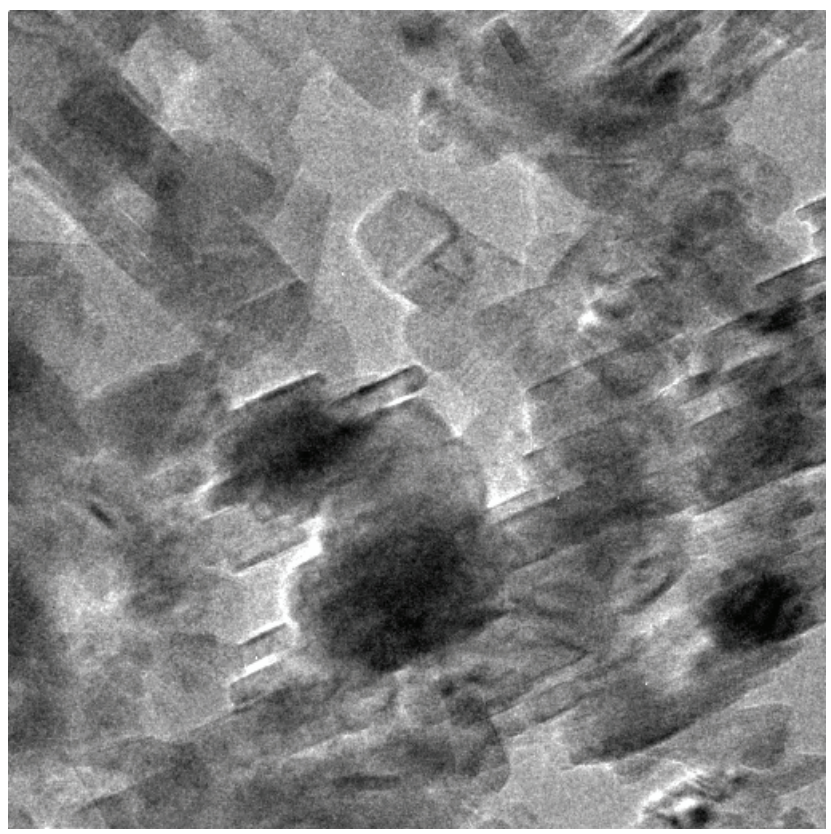

a)

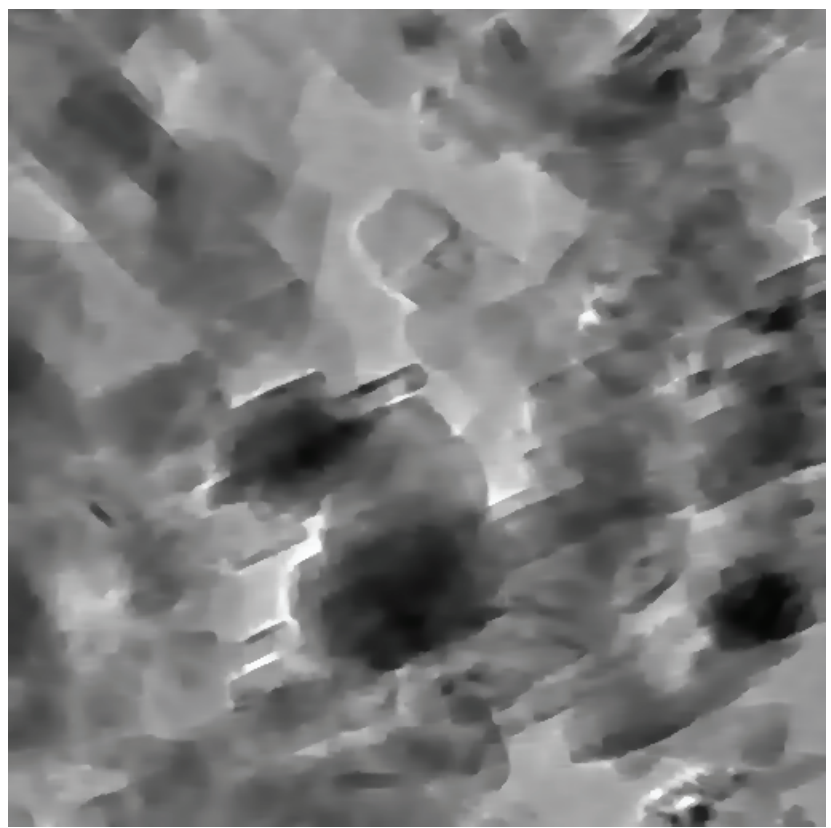

c) by reconstruction of size $3.3 \mathrm{~nm}$ is performed (Serra, 1982; Vincent, 1993) (Fig. 2d):

$$
O=\gamma_{\text {rec }}^{I}\left(\varepsilon_{3.3}(I)\right),
$$

with $\varepsilon_{3.3}(I)$ denoting a morphological erosion by a disc of diameter $3.3 \mathrm{~nm}$ and $\gamma_{\text {rec }}^{I^{\prime}}(I)$ denoting an opening by reconstruction of I in I'.

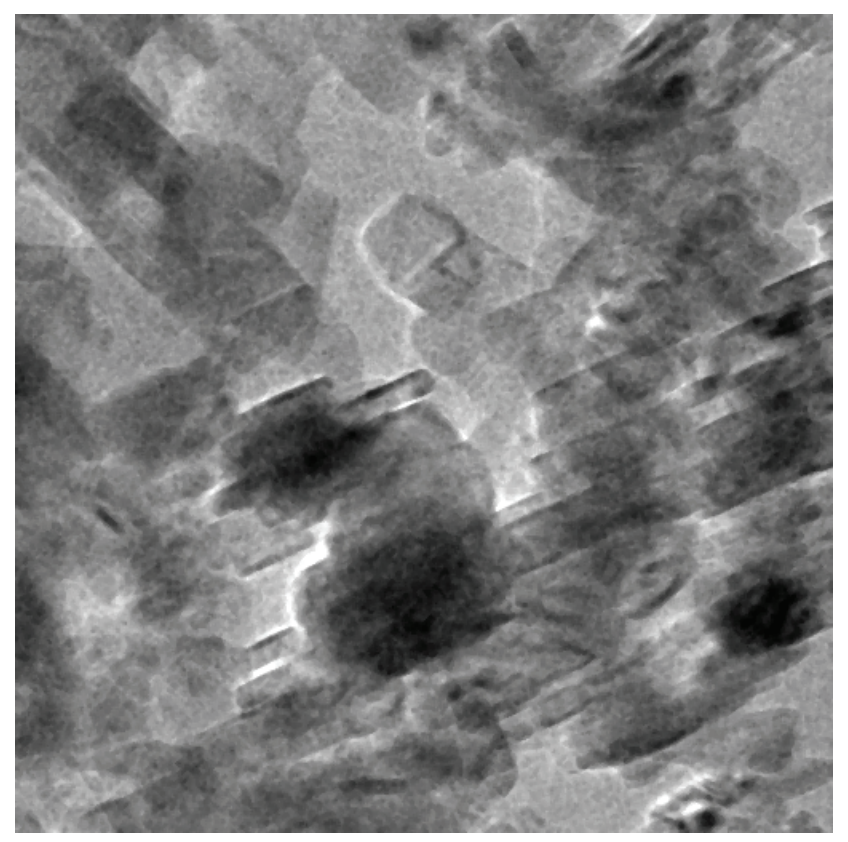

b)

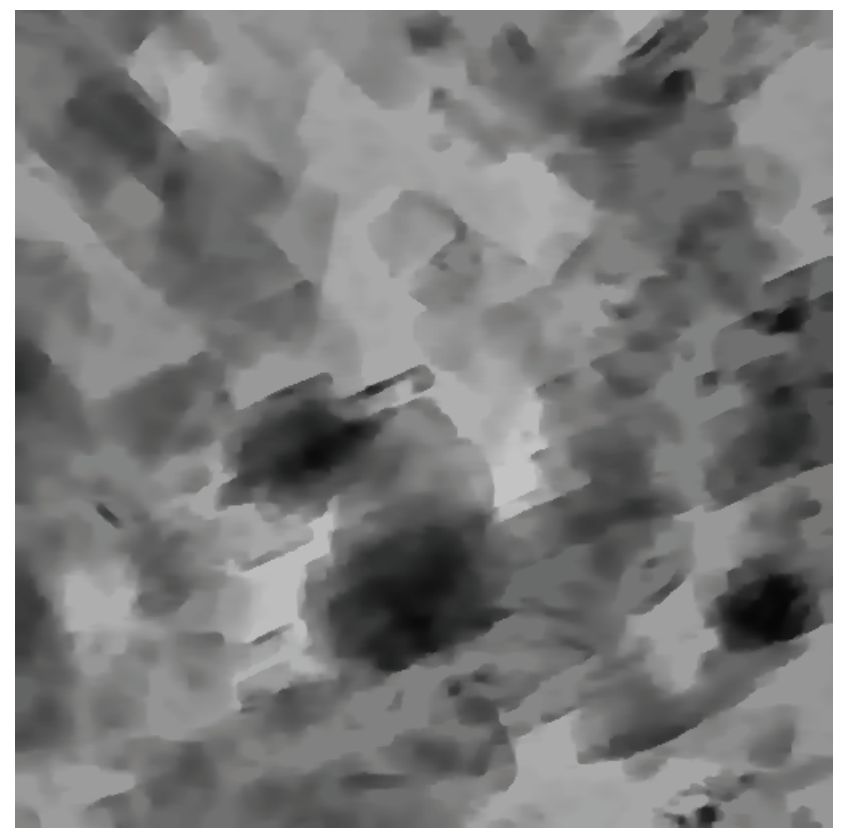

d)

Fig. 2. Steps to denoising and to remove white artefacts on the TEM images : a) initial image; b) image after a 3 by 3 median filter; c) image after a bilateral filter with parameters $\sigma_{f}=5$ and $\left.\sigma_{g}=20 ; d\right)$ image after the morphological opening by reconstruction of size $3.3 \mathrm{~nm}$. 


\section{MODELING USING A DILUTION MODEL}

A dilution model (Serra, 1968; Jeulin, 1991) can be used to simulate situations with thick slices with mass cumulation over the thickness. A dilution random function (DRF) is constructed from primary function $Z_{t}^{\prime}(x)$ and from a Poisson point process $P$ with intensity $\mu_{n}(d x) \otimes \theta(d t)$. The DRF is given by:

$$
Z_{i}(x)=\sum_{\left(t_{k}, x_{k}\right) \in P}\left\{Z_{i t_{k}}^{\prime}\left(x-x_{k}\right)\right\} .
$$

In what follows, we propose a modeling of the observations by means of this model.

The fraction of electrons $\mathrm{n}$ collected in one pixel in a bright field TEM image is given by (Hawkes, 2006): $\mathrm{n}=\exp \left(-\frac{\mu}{\mu_{\mathrm{t}}}\right)$ with $\mu=\rho . t$ mass thickness ( $\rho$ : density and $t$ : thickness) and $\mu_{t}=\frac{1}{N \sigma_{b f}}=$ cste $\left(\mathrm{N}\right.$ : (Avogadro's number)/(atomic weigh) and $\sigma_{\mathrm{bf}}$ scattering cross-section for bright field image). The intensity of a pixel is related to the density and to the atomic nature of the constituent projected point $\mathrm{x}$. In our case, the sample contains only one constituent, so the intensity is only a function of the local density of atoms of boehmite, i.e., the exponential of the local thickness of the boehmite nanoparticles. It is compatible with a modeling by means of a dilution model.

On the negative of the logarithm images, lighter the grey level intensity is, higher the thickness is. We have selected on the images 14 overlapping areas where only two nanoparticles overlap and we have checked that, with a relative mean error of $10 \%$, the average grey level intensity for two overlapping particles is two times higher than the average grey level intensity for only one particle. So an additive mass cumulation of boehmite nanoparticles over the thickness of the sample is observed. This is consistent with the assumption of a dilution model.

In this study, only the size distribution of boehmite nanoparticles is investigated and not the spatial distribution. To be compatible with a modeling using a one scale dilution model, only areas of the sample without aggregates of nanoparticles are analyzed.

\section{ANALYSIS AND RESULTS FROM COVARIANCE ANALYSIS}

Six images of size 512 x 512 with a resolution of $0.41 \mathrm{~nm} /$ pixel are used. For each image, the covariance function $\mathrm{C}$ for all directions of bi-points is calculated by means of Fourier Transform (Aubert and Jeulin, 2000; Karsten et al., 2003) (Fig. 3c):

$$
C(h)=F^{-1}\left[|F[I]|^{2}\right],
$$

with $F$ and $F^{-1}$ denoting respectively Fourier transform and inverse Fourier transform.

The obtained images of covariance do not present strong variations within angular directions: the distribution of the nanoparticles is isotropic. An average covariance curve can be obtained by radial transformation of $C(h)$ (Fig. 3d) and average within columns. Considering all images, an average covariance curve can be calculated (Fig. 3e).

After verifications made in the previous section, the images are supposed to be observations of the realizations of a dilution model with boehmite nanoparticles for primary grains. For a dilution model, the centered covariance is given by:

$$
\bar{C}(h)=\theta g(h),
$$

with $\theta$ and $g(h)$ denoting respectively the induced intensity in two dimensions of the 3D Poisson point process $\left(\theta=\theta_{3} e, \theta_{3}\right.$ being the 3D intensity and $e$ the thickness of the slice), and the transitive covariogram of the primary grains, i.e., in our case the boehmite nanoparticles.

For a dilution model, some results can be obtained by analysis of the covariance function. The range of this curve corresponds to the average size of the boehmite nanoparticles (Fig. 3e). The covariance curve normalized by the variance of the model (or the auto-correlation function) can be easily calculated. In the present case, the inverse of the slope at the origin of this curve is equal to the average intercept of the 2D projections of the primary grains (Fig. 3e). This value corresponds to the average intercept of the observed 2D projections of boehmites nanoparticles, namely $\frac{1}{4}\left(\frac{E\{S\}}{E\{M\}}\right)$, where $E\{S\}$ and $E\{M\}$ are the average of the surface area and of the integral mean curvature of the crystallites. The obtained results are presented in Table 1 and give average information 
about the size of the boehmite nanoparticles. The average size of $35 \mathrm{~nm}$ deduced from the range of the covariance for the boehmite nanoparticles is very close to the results of $40 \mathrm{~nm}$ obtained by X-ray diffraction analysis and given by Sasol Germany $\mathrm{GmbH}$, the provider of boehmite.

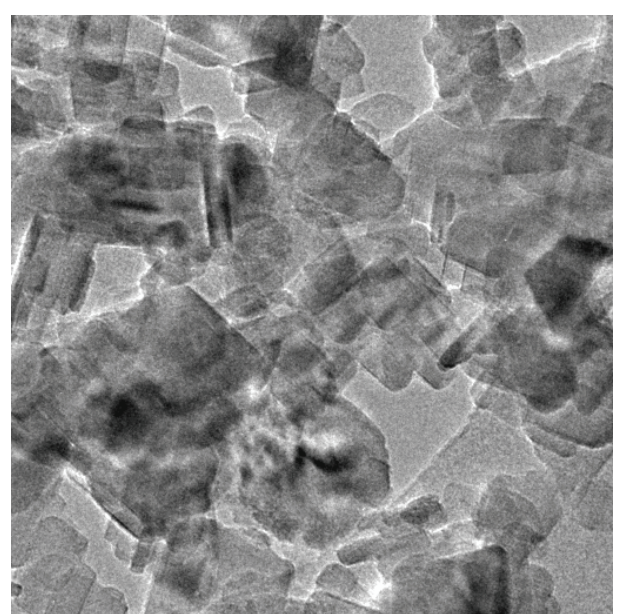

a)

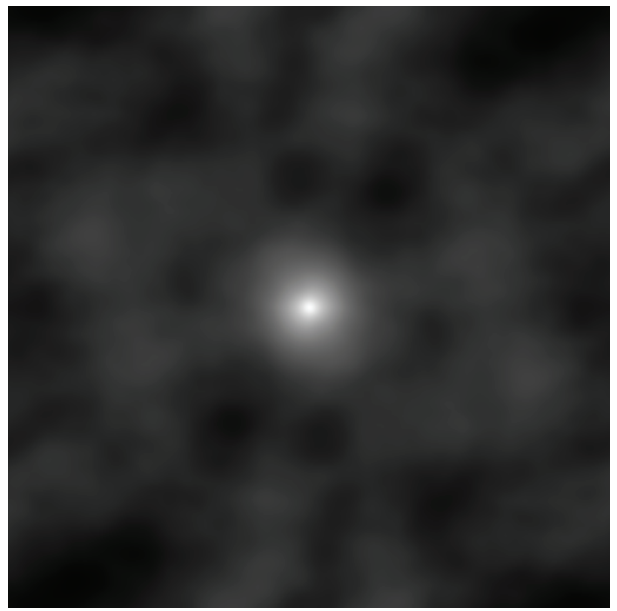

c)

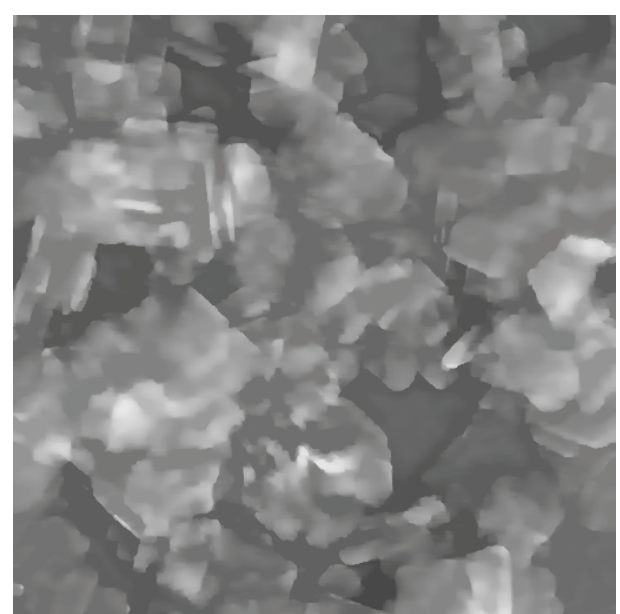

b)

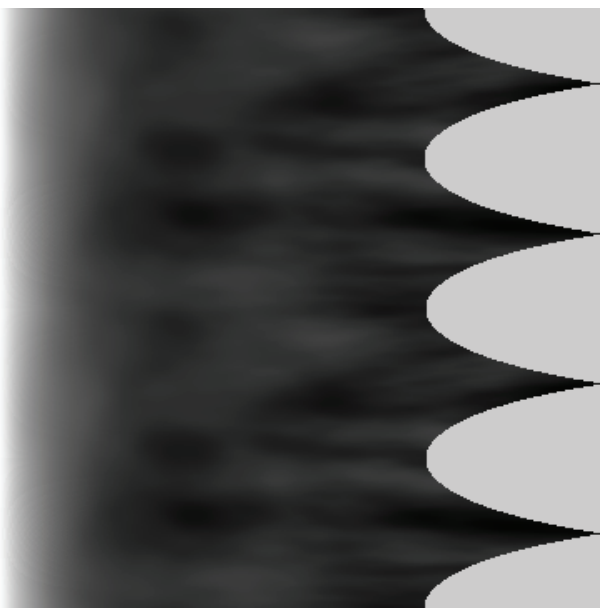

d)

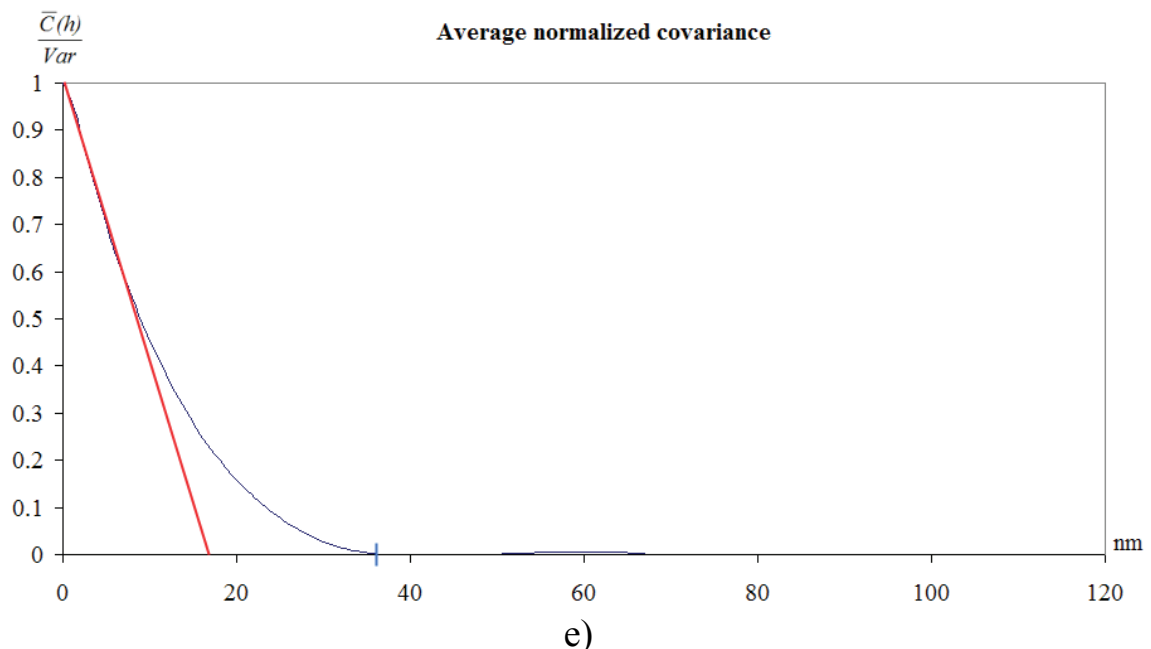

e)

Fig. 3. Calculation of the average covariance curve. a) initial image; b) negative filtered image; c) covariance image; d) radial covariance image; e) average normalized covariance curve (in blue, range; in red, slope at the origin). 
Table 1. Results obtained from the analysis of the covariance curve.

\begin{tabular}{l|l}
\hline $\begin{array}{l}\text { Average size of boehmite nanoparticles } \\
\text { deduced from the range of the covariance }\end{array}$ & $35 \mathrm{~nm}$ \\
\hline $\begin{array}{l}\text { Average intercept of the 2D projections of } \\
\text { boehmite nanoparticles }\end{array}$ & $17 \mathrm{~nm}$ \\
\hline
\end{tabular}

\section{CONCLUSION}

In this paper, a study of the average size of boehmite nanoparticles by means of TEM images is proposed. These images are denoised, and diffraction artifacts are removed by means of a sequence of adapted filters. Modeling of the observations by means of a dilution model is proposed and tested. Thanks to this model, some average information about the size of the nanoparticles can be extracted from the analysis of the covariance function calculated from the TEM images. These results are close to the result obtained by X-ray diffraction analysis. Further analysis of the covariance function are in progress with the use of the calculation of numerical transitive covariogram of a 3D geometric model of the boehmite nanoparticles, in order to estimate size distributions from TEM images.

\section{ACKNOWLEDGEMENT}

This paper is an extended version of a presentation in ECS10 (Milan, June 22-26, 2009).

\section{REFERENCES}

Ahmadi T, Wang Z, Green T, Henglein A, El-Sayed M (1996). Shape-controlled synthesis of colloidal platinum nanoparticles. Science 272:1924-5.

Arrouvel C, Toulhoat H, Breysse M, Raybaud P (2004). Effects of morphology on surface hydroxyl concentration: a DFT comparison of anatase- $\mathrm{TiO}_{2}$ and $\gamma$-alumina catalytic supports. J Catal 222:152-66.

Aubert A, Jeulin D (2000). Classification morphologique de surfaces rugueuses. Revue de Métallurgie - CIT/ Science et Génie des Matériaux, 2000:247-62.

Black M, Sapiro G, Marimont D, Heeger D (1998). Robust anisotropic diffusion. IEEE Trans. Image Proc. 7: 421-32.

Borchert H, Shevchenko E, Robert A, Mekis I, Kornowski A et al. (2005). Determination of nanocrystal sizes: A comparison of TEM, SAXS, and XRD studies of highly monodisperse CoPt3 particles. Langmuir 21: 1931-6.

Brus L (1991). Quantum crystallites and nonlinear optics. Appl Phys A 53:465-74.

Buffat P, Flüeli M, Spycher R, Stadelmann P, Borel J (1991). Crystallographic structure of small gold particles studied by high-resolution electron microscopy. Faraday Discuss 92:173-87.
Chiche D, Digne M, Revel R, Chanéac C, Jolivet J (2008). Accurate determination of oxide nanoparticle size and shape based on X-ray powder pattern simulation : application to boehmite AlOOH. J Phys Chem C 112: 8524.

Dessombz A, Chiche D, Davidson P, Panine P, Chanéac C (2007). Design of liquid-crystalline aqueous suspensions of rutile nanorods - Evidence of anisotropic photocatalystic properties. J Am Chem Soc 129:5904-9.

Digne M, Sautet P, Raybaud P, Euzen P, Toulhoat H (2002). Hydroxyl groups on gamma alumina surfaces: a DFT study. J Catal 211:1-5.

Dormann D, Fiorani D, Tronc E (1997). Magnetic relaxation in fine-particle systems. Adv Chem Phys 98:283-494.

Durand F, Dorsey J (2002). Fast bilateral filtering for the display of high dynamic-range images. SIGGRAPH '02. Proceedings of the 29th annual conference on Computer graphics and interactive techniques. ACM, 257-66.

Espinat D, Thevenot F, Grimoud J, El Malki K (1993). Powerful new software for the simulation of WAXS and SAXS diagrams. J Appl Cryst 26:368-83.

Euzen P, Raybaud P, Krokidis X, Toulhoat H, Le Loarer J et al. (2002). Alumina, in Handbook of porous solids In: Schüth F, Sing K, Weitkamp J, eds. Weinheim, Germany: Wiley-VCH Verlag GmbH, 3:1591-676.

Hawkes P (2006). The electron microscope as a structure projector. In: Frank JE, ed. Electron tomography: Threedimensional imaging with the transmission electron microscope. Plenum Press: New York: 83-112.

Jeulin D (1991). Modèles de fonctions aléatoires multivariables. Sci Terre 30:225-56.

Jolivet J, Chanéac C, Tronc E (2004a). Iron oxide chemistry. From molecular clusters to extended solid networks. Chem Commun 5:481-7.

Jolivet J, Froidefond C, Pottier A, Chanéac C, Cassaignon S et al. (2004b). Size tailoring of oxide nanoparticles by precipitation in aqueous medium. A semi-quantitative modelling. J Mater Chem 14:1-9.

Karsten K, Ohser J, Schladitz K (2003). Spectral theory for random closed sets and estimating the covariance via frequency space. Adv in Appl Probab 35:603-13.

Lemaire B, Davidson P, Ferré J, Jamet JP, Panine P et al. (2002). Magnetic properties of nematic suspensions of goethite (alpha -FeOOH) nanorods. Phys Rev Lett 88: 125507-11.

Moreaud M, Celse B, Tihay F (2008a). Analysis of the accessibility of macroporous alumino-silicate using 3D-TEM images. Proceedings of Materials Science \& Technology 2008 Conference and Exhibition: MS\&T'08: 1153-64.

Moreaud M, Jeulin D, Thorel A, Chane-Ching J (2008b). A quantitative morphological analysis of nanostructured ceria-silica composite catalysts. J Micros 232:295-305. 
Paris S, Durand F (2009). A fast approximation of the bilateral filter using a signal processing approach. Int $\mathrm{J}$ Comput Vision 81:24-52.

Pham T, van Vliet L (2005). Separable bilateral filtering for fast video preprocessing. Proc. ICME, IEEE Press: New York, 454-7.

Serra J (1968). Les fonctions aléatories de dilutino. N37CMM, Pais School of Mines Publication.

Serra J (1982). Image analysis and mathematical morphology. London: Academic Press.

Tomasi C, Manduchi R (1998). Bilateral filtering for gray and color images. Proc. of the Sixth International Conference on Computer Vision, IEEE press: Bombay, 839-46.

Vigolo B, Zakri C, Nallet F, Livage J, Coulon C (2002).
Detailed study of diluted $\mathrm{V}_{2} \mathrm{O}_{5}$ suspensions. Langmuir 18:9121.

Vincent L (1993). Morphological grayscale reconstruction in image analysis: Applications and efficient algorithms. IEEE Trans. Image Process 2:176-201.

Wagner J, Hartl W, Hempelmann R (2000). Characterization of monodisperse colloidal particles: Comparison between SAXS and DLS. Langmuir 16:4080-5.

Zhang D, Sun LI, Yin Y, Yan C (2003). Low-temperature fabrication of highly crystalline $\mathrm{SnO}_{2}$ nanorods. Ad Mater 15:1022-5.

Ziese U, de Jong K, Koster A (2004). Electron tomography: a tool for 3D structural probing of heterogeneous catalysts at the nanometer scale. Appl Catal A-General 260:71-4. 